\title{
Maternal adaptations to pregnancy in spontaneously hypertensive rats: leptin and ghrelin evaluation
}

\author{
Giuseppina Mattace Raso, Giuseppe Bianco ${ }^{1}$, Anna lacono, Emanuela Esposito, Giuseppina Autore ${ }^{1}$, \\ Maria Carmela Ferrante ${ }^{2}$, Antonio Calignano and Rosaria Meli
}

Department of Experimental Pharmacology, University of Naples, 'Federico II', via D. Montesano, 49-80131 Naples, Italy

${ }^{1}$ Department of Pharmaceutical Sciences, University of Salerno, 'Federico II', Naples, Italy

${ }^{2}$ Department of Pathology and Animal Health, University of Naples 'Federico II', Naples, Italy

(Correspondence should be addressed to R Meli; Email: meli@unina.it)

\begin{abstract}
Leptin and/or ghrelin, initially thought to be considered messengers of energy metabolism, are now considered to play a role in normal and complicated pregnancy. In this study, pregnant, spontaneously hypertensive rats (SHR) have been used to evaluate, for the first time, the modification of leptin and ghrelin both at serum and tissue levels. In SHR, we evaluate plasma leptin level and tissue protein expression in both placenta and adipose tissue at the end of gestation (day 20) versus normotensive Wistar-Kyoto (WKY) animals. The expression of functional leptin receptor $(\mathrm{Ob}-\mathrm{Rb})$ in peripheral tissues and in the hypothalamus was evaluated. Moreover, we measured plasma ghrelin level and its mRNA expression in the stomach and placenta. SHR strain presented significantly lower plasma leptin levels when compared with those found in pregnant or not WKY controls. Interestingly, in the placenta, leptin gene
\end{abstract}

expression was higher in SHR than normotensive WKY. Moreover, we demonstrated a resistance to the effects of leptin via 'downregulation' of hypothalamic receptors in pregnant SHR. Conversely, SHR presented significantly higher ghrelin plasma levels when compared with those found in pregnant or not WKY. However, we observed that ghrelin level in the stomach of SHR did not change during pregnancy, and on the opposite, mRNA ghrelin in the placenta of SHR was lower than that of normotensive rats, suggesting a different production of this hormone in the fetal-placental unit. These data gain further insight into metabolic hormone modifications observed in a model of pre-existing hypertension associated with pregnancy.

Journal of Endocrinology (2007) 194, 611-619

\section{Introduction}

During pregnancy, several neuroendocrine changes and energy metabolism alterations occur. In this hypermetabolic state, a great increase in maternal body fat and weight and a positive energy balance are well recognized, primarily to prevent the depletion of maternal energy stores (Richard \& Trayhurn 1985).

Leptin $(\mathrm{Ob})$, the product of the ob gene, is thought to play a critical role in the regulation of adipose tissue mass, and may directly or indirectly influence reproductive function. It is now recognized that leptin is produced in several organs and tissues besides white adipose tissue, such as heart, mammary epithelial cells, and placenta. This hormone inhibits food intake, regulates energy expenditure, is a permissive signal to the reproductive system, and is a metabolic hormone affecting insulin secretion, lipolysis, and sugar transport (Trayhurn et al. 1999). Leptin has been proposed as a lipostatic factor that regulates the amount of body fat stores by means of a closed feedback loop involving the hypothalamus (Erickson et al. 1996, Rohner Jean Reaneaud et al. 1996).
Leptin affects body weight and reproduction mainly by interacting with specific receptors $(\mathrm{Ob}-\mathrm{R})$, which use the JAK/STAT pathway of signal transduction. Different isoforms of the Ob-R exist, including a long isoform $(\mathrm{Ob}-\mathrm{Rb})$ with signaling capacity and short isoforms with several and not completely known functions. In particular, $\mathrm{Ob}-\mathrm{Rb}$ is expressed in a wide range of tissues including hypothalamus (Tartaglia 1997).

Recent reports have demonstrated that leptin levels are elevated in serum during human and rodent gestation (Henson \& Castracane 2006). In particular, during pregnancy in rats, the high levels of leptin indicate the existence of a physiological state of central leptin resistance that might explain the increased food intake observed during gestation (Garcia et al. 2000).

In humans, a potential role of maternal leptin concentration as a marker of pre-eclampsia, a form of pregnancyinduced hypertension, has been suggested. In fact, maternal leptinemia is significantly higher in pregnancies complicated by pre-eclampsia than in gestational age-matched controls (Teppa et al. 2000). Moreover, the increase of hormone level 
predates the development of pre-eclampsia (Anim-Nyame et al. 2000), and it has been shown that leptin gene expression in the placenta is augmented in severe pre-eclampsia (Laivouri et al. 2006) and that a dysregulation of autocrine and paracrine function of leptin in fetal-maternal interface can be implicated not only in pregnancy-induced hypertension, but also in gestational diabetes and in the intrauterine growth retardation, including disturbance of fetal bone (Bajoria et al. 2002).

It has recently been reported that ghrelin, a gastric-derived peptide, plays an important role in the reproductive function both in animals (Gualillo et al. 2002, Caminos et al. 2003) and in humans (Gaytan et al. 2003). In the CNS, this hormone induces growth hormone $(\mathrm{GH})$ release and interacts with hypothalamic nuclei, stimulating feeding and determining body weight gain (Wren et al. 2000). Ghrelin augments neuropeptide $\mathrm{Y}$ gene expression and blocks leptin-induced feeding reduction, implying that there is a competitive interaction between ghrelin and leptin in feeding regulation (Nakazato et al. 2001).

Ghrelin is also synthesized by placenta and its secretion might influence the fetal growth and maturation. During pregnancy in rats, the maternal concentration of plasma ghrelin is significantly lower than that of nonpregnant animals, even if ghrelin peptide concentrations in the stomach did not change significantly during pregnancy (Shibata et al. 2004).

Since pre-existing hypertension is included among hypertensive disorders of pregnancy, we used spontaneously hypertensive rats (SHR) in order to evaluate prospective metabolic and hormonal differences or modifications. In particular, here we compared plasma leptin and its protein expression in placenta and adipose tissue at the end of gestation in normal (Wistar-Kyoto, WKY) and SHR animals. Differential regulation of the $\mathrm{Ob}-\mathrm{R}$ expression in peripheral tissues and in the hypothalamus of SHR and WKY rats was also evaluated. Moreover, we also measured plasma ghrelin level at the end of pregnancy and mRNA in the stomach and placenta.

\section{Material and Methods}

\section{Animals}

Twenty-week-old female normotensive WKY (average body weight of the cohort, 208 $\pm 3 \mathrm{~g}$ ) and SHR (average body weight of the cohort, $212 \cdot 0 \pm 2$ g; Harlan Italy, San Pietro al Natisone, Udine, Italy) were housed one per cage in stainless steel cages in a room kept at $22 \pm 1^{\circ} \mathrm{C}$ with a $12 \mathrm{~h}$ light: $12 \mathrm{~h}$ darkness cycle. The animals had access to tap water and rodent standard diet and were allowed to feed ad libitum.

Estrus cycle was assessed to determine the reproductive status. SHR and WKY virgin female rats ( $n=5$ per group) were mated at estrous, and the day of mating determined by the presence of spermatozoa after a vaginal smear, being considered day 0 of pregnancy. Same number of virgin WKY and SHR of the same age served as controls.
All animal experiments complied with the Italian D.L. no. 116 of January 27, 1992 and associated guidelines in the European Communities Council Directive of November 24, 1986 (86/609/ECC).

\section{Body weight, food intake, and body gain in fat}

Throughout pregnancy, body weight and food intake were monitored once a week $(6,14$, and 20 days). At the end of the experimental period, food intakes were cumulated. Bioelectrical impedance analysis (BIA) was applied to body composition assessment at day 20 by a BIA 101 analyzer, modified for rat (Akern, Florence, Italy). Free fat mass was calculated by the BIA $(50 \mathrm{kHz})$ prediction equation of Ilagan et al. (1993), and fat mass content was obtained as the difference between body weight and free fat mass.

\section{Measurement of arterial blood pressure indirectly in conscious rat}

Mean arterial blood pressure in conscious rats was measured by a Blood Pressure Recorder (Ugo Basile, Biological Research Apparatus, 21025 Comerio, Italy) using a technique described by Gerold \& Tschirky (1968). After 2 weeks training period, blood pressure was measured before mating and at 6,14, and 20 days of pregnancy. To measure arterial blood pressure, rats were housed for $30 \mathrm{~min}$ in a warmed room $\left(28-30{ }^{\circ} \mathrm{C}\right)$, then a tail cuff, placed about $2 \mathrm{~cm}$ from the base of the tail, measured arterial blood pressure.

\section{Tissue collection and blood parameters}

At day 20 of pregnancy, animals were anesthetized by enflurane and killed by cervical dislocation. Control animals were killed at the second day of diestrus. Blood collected by cardiac puncture was centrifuged at $1500 \mathrm{~g}$, at $4{ }^{\circ} \mathrm{C}$ for $15 \mathrm{~min}$, and sera were stored at $-70{ }^{\circ} \mathrm{C}$ for later biochemical and hormonal measurements.

Glucose, high-density lipoprotein (HDL), low-density lipoprotein (LDL), triglycerides, and cholesterol were quantified using nonfasting blood sample. The serum leptin and ghrelin (the bioactive form of the hormone, $n$-octanoyl modified in $\mathrm{Ser}^{3}$ ) concentrations were measured by RIA kits according to the manufacturer's instruction (Linco Research Inc., St Charles, MO, USA).

Subcutaneous white adipose tissue, stomach, placenta, and hypothalamus (dissected according to the map of Glowinski \& Iversen (1966)) were excised and immediately frozen in liquid nitrogen.

\section{Western blot analysis}

The s.c. adipose tissue, hypothalamus, and placenta obtained from each animal were disrupted by homogenization on ice in lysis buffer (20 mM Tris-HCl (pH 7.5), $10 \mathrm{mM} \mathrm{NaF}$, $150 \mathrm{mM} \mathrm{NaCl}, 1 \%$ Nonidet P-40, $1 \mathrm{mM}$ phenylmethylsulfonyl fluoride, $1 \mathrm{mM} \mathrm{Na} \mathrm{VO}_{4}$, and $10 \mu \mathrm{g} / \mathrm{ml}$ leupeptin 
and trypsin inhibitor). After $1 \mathrm{~h}$, tissue lysates were obtained by centrifugation at $100000 \mathrm{~g}$ for $15 \mathrm{~min}$ at $4{ }^{\circ} \mathrm{C}$. Protein concentrations were estimated by the Bio-Rad protein assay (Bio-Rad Laboratories) using BSA as standard.

For western blot analysis, $100 \mu \mathrm{g}$ protein of all tissue lysates were dissolved in Laemmli sample buffer, boiled for $5 \mathrm{~min}$, and subjected to SDS-PAGE ( 8 or $12 \%$ polyacrylamide). The blot was performed by transferring proteins from a slab gel to nitrocellulose membrane at $240 \mathrm{~mA}$ for $40 \mathrm{~min}$ at room temperature. The filter was then blocked with $1 \times$ PBS, $5 \%$ nonfat dried milk for $40 \mathrm{~min}$ at room temperature, and probed with a goat polyclonal anti-C-term $\mathrm{Ob}-\mathrm{Rb}$ antibody (1:1000; Santa Cruz Biotechnology Inc., Santa Cruz, CA, USA), or with rabbit polyclonal anti-Ob antibody (1:1000; Santa Cruz Biotechnology Inc.) in $1 \times$ PBS, $5 \%$ nonfat dried milk, and $0 \cdot 1 \%$ Tween 20 at $4{ }^{\circ} \mathrm{C}$ overnight. The secondary antibody (anti-rabbit or anti-goat IgG-horseradish peroxidase conjugate 1:2000 dilution) was incubated for $1 \mathrm{~h}$ at room temperature. Subsequently, the blot was extensively washed with PBS, developed using enhanced chemiluminescence detection reagents (Amersham Pharmacia Biotech) according to the manufacturer's instructions, and exposed to Kodak X-OMAT film (Eastman Kodak Co). To ascertain that blots were loaded with equal amounts of protein lysates, they were also incubated in the presence of the antibody against the $\beta$-actin protein (Sigma). The protein bands of $\mathrm{Ob}$ and $\mathrm{Ob}-\mathrm{Rb}$ ( $\sim 16$ and $130 \mathrm{kDa}$ respectively) on X-ray film were scanned and densitometrically analyzed with a model GS-700 imaging densitometer (Bio-Rad Laboratories).

\section{RT-PCR analysis}

Total RNA was extracted by a modified method of Chomczynski \& Sacchi (1987), using TRIzol Reagent (Life Technologies) according to the manufacturer's instructions. Reverse transcription was performed by a standard procedure (Brenner et al. 1989) using $2 \mu \mathrm{g}$ total RNA. After reverse transcription, $2 \mu \mathrm{RT}$ products were diluted in $48 \mu \mathrm{l} \mathrm{PCR} \mathrm{mix,}$ to give a final concentration of $50 \mathrm{U} / \mathrm{ml} \mathrm{Taq} \mathrm{DNA} \mathrm{polymerase}$ (Life Technologies), $4 \mu \mathrm{M} 5^{\prime}$ and $3^{\prime}$ primers, $50 \mu \mathrm{M}$ each dNTP, $1.5 \mathrm{mM} \mathrm{MgCl}_{2}$, and $1 \times$ PCR buffer $(20 \mathrm{mM}$ Tris- $\mathrm{HCl}$ (pH 8.4), $50 \mathrm{mM} \mathrm{KCl}$. The following oligonucleotides were used: ghrelin (forward primer 5'-TTGAGCCCAGAGCACCAGAAA- $3^{\prime}$ and reverse primer $5^{\prime}$-AGTTGCAGAGGAGGCAGAAGCT- $3^{\prime}$ ) and $\beta$-actin (forward primer $5^{\prime}$-TACAACTCCTTGCAGCTCC- $3^{\prime}$ and reverse primer $5^{\prime}$-ATCTTCATGAGGTAGTCAGTC-3'). PCR primers were synthesized by 'Servizio di Biologia Molecolare, Stazione Zoologica A. Dohrn' (Naples, Italy). The amplification profile for rat ghrelin and $\beta$-actin was: denaturation at $98^{\circ} \mathrm{C}$ for $10 \mathrm{~s}$, annealing at $55^{\circ} \mathrm{C}$ for $30 \mathrm{~s}$, and extension at $72{ }^{\circ} \mathrm{C}$ for $1 \mathrm{~min}$. A 35-cycle amplification was completed with an additional step at $72{ }^{\circ} \mathrm{C}$ for $10 \mathrm{~min}$. The amplification was performed in an automatic thermal cycler (Biometra, Göttingen Germany). To assure that PCR was performed in the linear amplification range, samples were taken after 15, 20, 25, 30, 35, and 40 cycles, showing that the reaction was linear over this range (data not shown). Then $10 \mu \mathrm{R}$ RT-PCR products were separated by $1.5 \%$ agarose gel electrophoresis in TBE $1 \times(10.089 \mathrm{M}$ Tris base, $0.089 \mathrm{M}$ boric acid) containing $0.2 \mu \mathrm{g} / \mathrm{ml}$ ethidium bromide. Fragments of DNA were seen under u.v. light. $\beta$-Actin was used as an internal reference. PCR generates a single 347 bp product for rat ghrelin and a single $603 \mathrm{bp}$ product for the $\beta$-actin gene. The bands of ghrelin were scanned and densitometrically analyzed with a model GS-700 imaging densitometer (Bio-Rad Laboratories).

\section{Statistical analysis}

All data were presented as mean \pm s.E.M. Statistical analysis was performed by ANOVA test for multiple comparisons, followed by Bonferroni's test. Statistical significance was set at $P<0 \cdot 05$.

To better understand statistical significance, we conventionally used the following symbols: to compare the examined group versus WKY-NP; ${ }^{\circ}$, to compare SHR-P versus SHRNP; and \#, to compare SHR-P versus WKY-P.

\section{Results}

Body weight gain, food intake, and body fat modifications in hypertensive and normotensive rats during pregnancy

Body weight gain, food intake, and fat mass of the normotensive and hypertensive rats are presented in Fig. 1. Pregnancy in normotensive as well as hypertensive rats induced a significant increase $(P<0 \cdot 001)$ in body weight gain (Fig. 1A), food intake (Fig. 1B), and fat mass (Fig. 1C).

Interestingly, SHR-NP showed a significant increase of food intake when compared with WKY-NP $(P<0 \cdot 001)$. This parameter was evaluated as area under curve of the amount of food consumed in 20 days. However, in SHR-P, there was a significant increase in body weight gain when compared with that of WKY-P $(P<0 \cdot 01)$, that was paralleled by a significant increase in fat mass content $(P<0 \cdot 001)$.

\section{Systolic blood pressure in pregnant or not WKY and SHR animals}

The mean values of systolic blood pressure detected during the experimental period for both SHR and WKY rats are shown in Fig. 2. No differences in blood pressure were observed in WKY-P when compared with WKY-NP rats (panel A). In SHR-P, this parameter was significantly reduced at day 14 of pregnancy when compared with SHR-NP $(P<0.05)$, and the fall was more marked at day 20 $(P<0 \cdot 001)$, where blood pressure reading became similar to normotensive pregnant rats.

\section{Hormone levels and blood parameters}

Determination of plasma leptin and ghrelin levels of all groups was shown in Fig. 3A and B respectively. In our experimental 


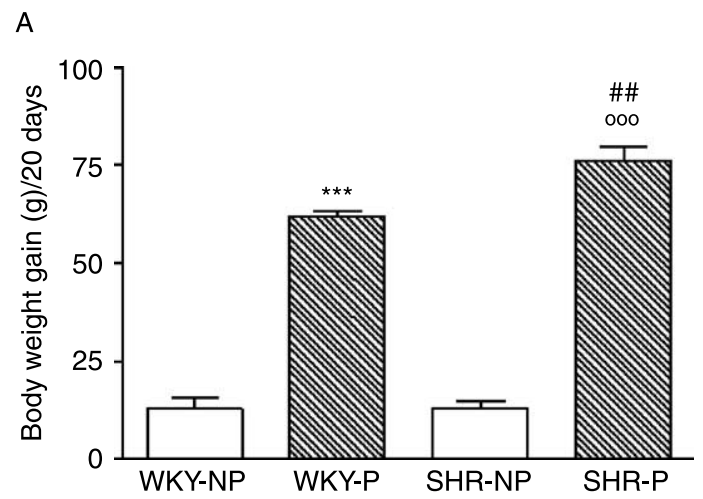

B

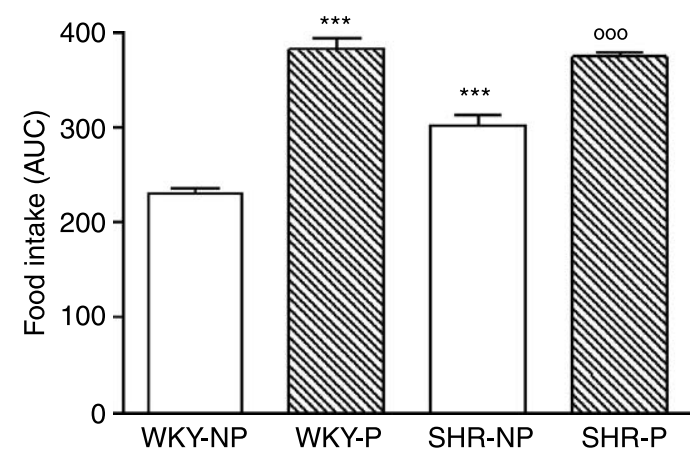

C

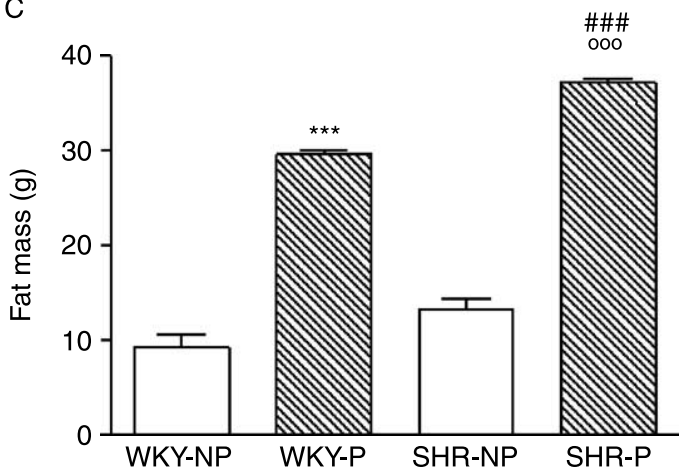

Figure 1 Changes in (A) body weight gain, (B) food intake, and $(C)$ fat mass of nonpregnant (-NP) or pregnant (-P) hypertensive (SHR) and normotensive $(\mathrm{WKY})$ rats. Values are mean \pm S.E.M. of five animals. AUC, area under the curve. ${ }^{* * *} P<0 \cdot 001$ versus WKY-NP; ${ }^{\circ 00} P<0 \cdot 001$ versus SHR-NP; ${ }^{\#} P<0 \cdot 01$ and ${ }^{\# \# \#} P<0 \cdot 001$ versus WKY-P.

conditions, SHR strain animals presented a lower level of plasma leptin versus that of the respective WKY controls $(P<0 \cdot 001)$. Leptin level $(\mathrm{ng} / \mathrm{ml})$, measured at gestational day 20 , did not significantly change in comparison with nonpregnant respective controls $(3 \cdot 30 \pm 0 \cdot 10$ vs $3 \cdot 00 \pm 0 \cdot 21$ in WKY rats, and $1 \cdot 16 \pm$ 0.14 vs $0.56 \pm 0.57$ in SHR). Conversely, plasma ghrelin is higher in SHR when compared with WKYanimals $(P<0 \cdot 001)$. Neither pregnant group had different plasma ghrelin levels than their respective nonpregnant controls.

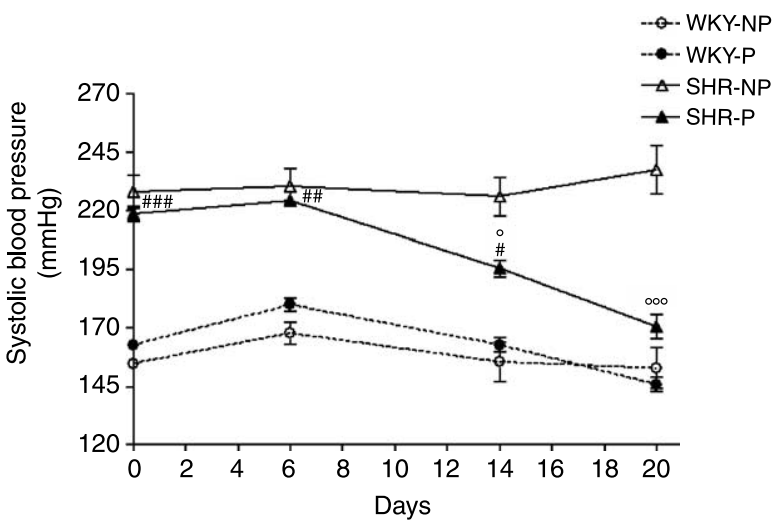

Figure 2 Systolic blood pressure levels of nonpregnant (-NP) or pregnant (-P) hypertensive (SHR) and normotensive (WKY) rats measured at $0,6,14$, and 20 days. The results are expressed as mean \pm S.E.M. of five animals. ${ }^{\circ} P<0 \cdot 05$, and ${ }^{\circ 00} P<0 \cdot 001$ versus SHR-NP; ${ }^{\sharp} P<0 \cdot 05,{ }^{\#} P<0 \cdot 01$, and $\# \# P<0 \cdot 001$ versus WKY-P.

In Table 1 , modifications of serum parameters are reported. Cholesterol, triglycerides, and glucose were similar in nonpregnant SHR and WKY rats. Conversely, SHR-NP presented a significantly reduced plasma LDL cholesterol and a higher HDL cholesterol when compared with that of WKYNP $(P<0.05$ and $P<0 \cdot 01$ respectively). In normotensive animals, pregnancy induced a significant decrease of total cholesterol $(P<0 \cdot 01)$, LDL cholesterol $(P<0 \cdot 001)$, and glucose $(P<0 \cdot 05)$, and an increase of plasma triglycerides $(P<0 \cdot 05)$. In SHR-P, all these parameters were similarly modified; in particular, a very strong increase of triglycerides was observed when compared with WKY-P $(P<0 \cdot 001)$.

$O b$ expression in adipose tissue and placenta from $W K Y$ and SHR animals

Figure 4A shows that s.c. adipose tissue from SHR presented a slight reduction of leptin expression when compared with that of WKY rats; moreover, pregnancy in normotensive as well as hypertensive rats induced a significant increase $(P<0.01$ and $P<0.05$ respectively $)$ in $\mathrm{Ob}$ expression versus their respective nonpregnant controls. $\mathrm{Ob}$ protein in WKY-P tissue lysates was more expressed than in SHR-P. Conversely, as appears in Fig. 4B, Ob expression in placentas of SHR-P was increased $(P<0 \cdot 01)$ in comparison with WKY-P animals.

$\mathrm{Ob}-\mathrm{Rb}$ expression in s.c. adipose tissue and hypothalamus from WKY and SHR animals

The expression of the functional isoform of $\mathrm{Ob}-\mathrm{R}, \mathrm{Ob}-\mathrm{Rb}$, in the adipose tissue and hypothalamus is reported in Fig. 5A and $\mathrm{B}$. In adipose tissue, there was no significant modulation of $\mathrm{Ob}-\mathrm{Rb}$ expression in any group, but a trend of $\mathrm{Ob}-\mathrm{Rb}$ decreased expression was revealed in both pregnant groups 

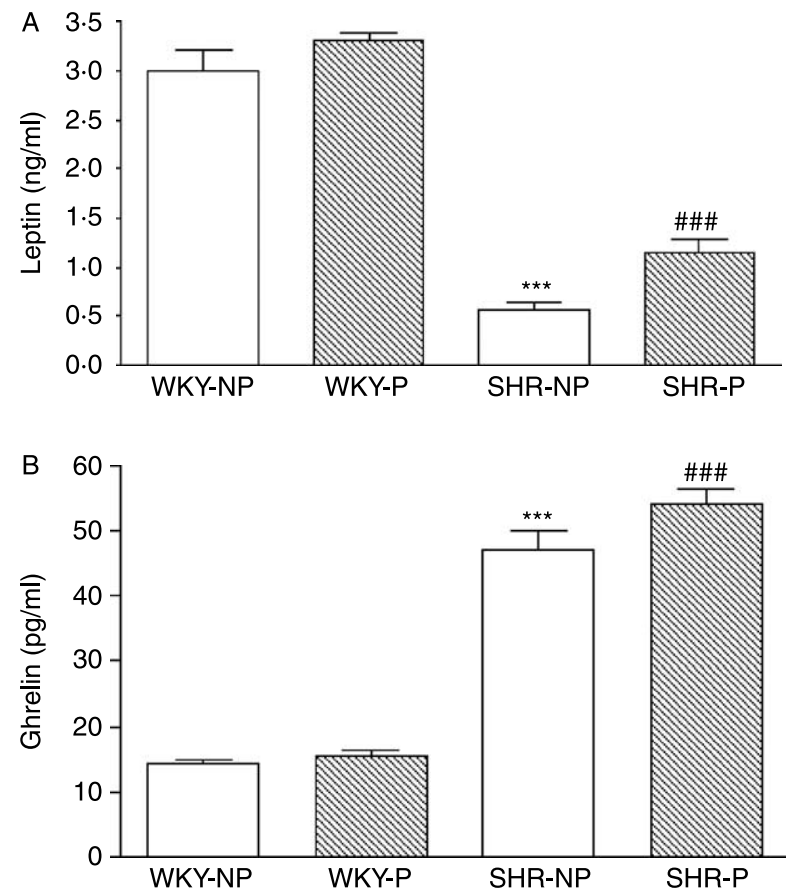

Figure 3 Changes in circulating plasma (A) leptin and (B) ghrelin in nonpregnant $(-\mathrm{NP})$ or pregnant $(-\mathrm{P})$ hypertensive $(\mathrm{SHR})$ or normotensive $(W K Y)$ rats. Values are mean \pm S.E.M. of five animals. ${ }_{* * *} P<0.001$ versus WKY-NP; and ${ }^{\# \#} P<0.001$ versus WKY-P.

versus their respective controls (Fig. 5A). Hypothalamus from SHR strain animals had a reduced expression of $\mathrm{Ob}-\mathrm{Rb}$ $(P<0 \cdot 05)$ when compared with that of normotensive WKY rats. The same pattern was found during pregnancy, where $\mathrm{Ob}-\mathrm{Rb}$ continued to be underexpressed when compared with WKY-P $(P<0 \cdot 05)$.

\section{Ghrelin $m R N A$ expression in stomach and placenta from} pregnant $W K Y$ and SHR animals

In stomach, no difference in ghrelin mRNA expression was observed between normotensive and hypertensive rats (Fig. 6A). Conversely, a significant reduction $(P<0 \cdot 05)$ of ghrelin expression in placenta from SHR-P was evidenced (Fig. 6B).

\section{Discussion}

During pregnancy, physiological adaptation in the nutritional and hormonal setting is necessary for fetal growth and maternal well-being. When pathological conditions, such as obesity or hypertension, occur, further modifications are needed to avoid maternal complications or fetal programming. Moderate hypertension tends to happen at the end of the pregnancy and does not represent a serious disturbance. Hypertensive disorders of pregnancy include pre-existing hypertension and pregnancy-induced hypertension. In this study, the SHRs were used for an experimental model of pregnancy associated with pre-existing hypertension in order to evaluate some metabolic and hormonal modifications. SHRs are a genetic animal model of hypertension widely used in medical research because of the features they share with idiopathic hypertension in humans (Okamoto \& Aoki 1963). Even if, differently from pre-eclampsia, no edema and only a small amount of proteinuria were observed in SHR (Yamada et al. 1981), the behavior of blood pressure during pregnancy has been a matter of controversy in the literature.

Unlike another study (Tanigawa et al. 1999), the normotensive pregnant rats that we examined showed no change in blood pressure during the gestational period. Conversely, we found that in SHR, pregnancy remarkably reduced pressure at delivery, confirming previous data (Zamorano et al. 1980, Lindheimer et al. 1983, Ahokas \& Sibai 1990). The pressure decrease near term was not associated with an alteration of insulin resistance (Tanigawa et al. 1999) and could be related to an increase of nitric oxide in pregnancy (Conrad et al. 1993), or the release of hypotensive substances by the placenta (Nakanishi et al. 1980), or the modification of the reninangiotensin system (Ahokas et al. 1989).

Leptin and/or ghrelin, initially thought to be considered messengers of energy metabolism, are now deemed to play a role in normal and complicated pregnancy (Makino et al. 2002, Henson \& Castracane 2006). During pregnancy, the increase of leptin level in human correlates with a higher expression of the leptin gene in placenta (Masuzaki et al. 1997). Contrasting data are reported about the main source of leptin in rat; some authors indicate adipose tissue as the main source of leptin also during pregnancy because lack of leptin expression was reported in placenta (Kawai et al. 1997). Other

Table 1 Modifications of serum parameters of nonpregnant (-NP) or pregnant (-P) spontaneously hypertensive rats (SHR) and Wistar-Kyoto (WKY) rats. Values are the mean \pm S.E.M.

\begin{tabular}{|c|c|c|c|c|c|}
\hline & Cholesterol (mg/dl) & LDL (mg/dl) & HDL (mg/dl) & Triglycerides $(\mathrm{mg} / \mathrm{dl})$ & Glucose $(\mathrm{mg} / \mathrm{dl})$ \\
\hline \multicolumn{6}{|l|}{ Groups } \\
\hline WKY-NP & $124 \cdot 0 \pm 4 \cdot 7$ & $77 \cdot 8 \pm 4 \cdot 4$ & $29 \cdot 8 \pm 0 \cdot 9$ & $82 \cdot 2 \pm 8 \cdot 1$ & $152 \cdot 20 \pm 12 \cdot 00$ \\
\hline WKY-P & $102 \cdot 8 \pm 1 \cdot 4^{+}$ & $37 \cdot 6 \pm 0 \cdot 8^{\neq}$ & $33 \cdot 0 \pm 1 \cdot 0$ & $165 \cdot 4 \pm 2 \cdot 2^{*}$ & $99 \cdot 60 \pm 2 \cdot 25^{*}$ \\
\hline SHR-NP & $120 \cdot 0 \pm 4 \cdot 1$ & $63 \cdot 0 \pm 2 \cdot 5^{*}$ & $37 \cdot 8 \pm 1 \cdot 5^{+}$ & $86 \cdot 2 \pm 6 \cdot 7$ & $165 \cdot 40 \pm 12 \cdot 45$ \\
\hline SHR-P & $97 \cdot 6 \pm 3 \cdot 5^{+}$ & $\mathrm{NC}$ & $31 \cdot 6 \pm 1 \cdot 5$ & $440 \cdot 8 \pm 40 \cdot 0^{\|, \pi}$ & $124 \cdot 60 \pm 8 \cdot 29$ \\
\hline
\end{tabular}

${ }^{*} P<0 \cdot 05,{ }^{\dagger} P<0 \cdot 01$, and ${ }^{\ddagger} P<0 \cdot 001$ versus WKY-NP; $" P<0 \cdot 001$ versus SHR-NP; ${ }^{\circledR} P<0 \cdot 001$ versus WKY-P; NC, not calculable. 
A
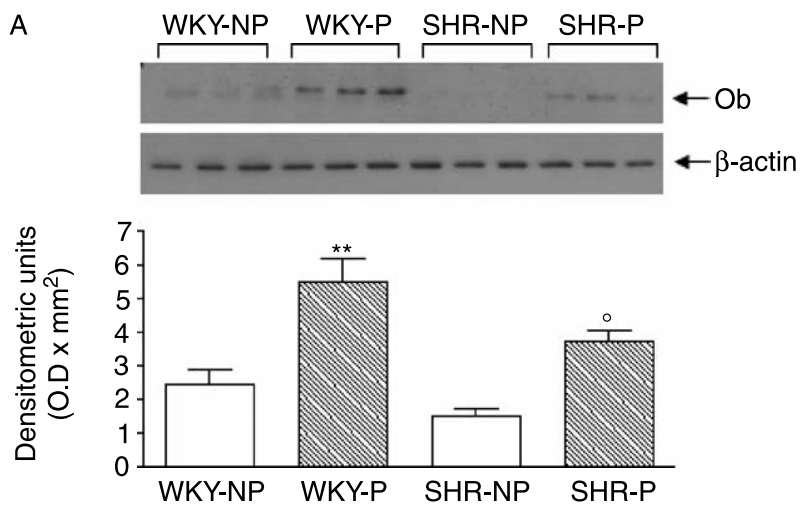

B
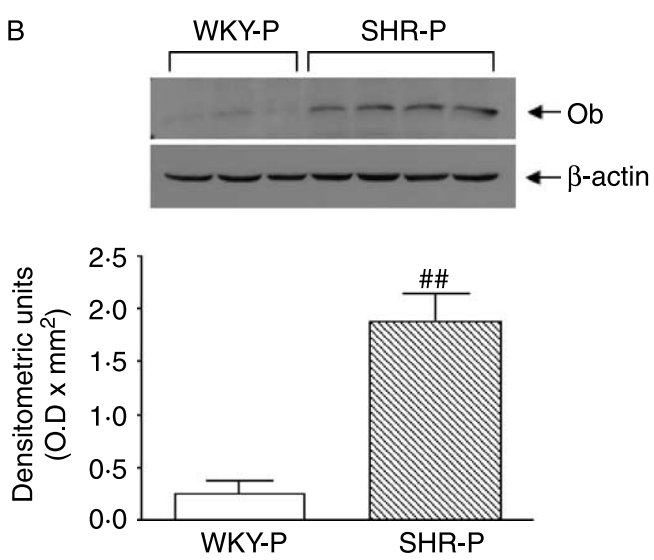

Figure 4 Western blot analysis of Ob expression and densitometric analysis of protein bands in (A) s.c. adipose tissue and (B) placenta. (A) Shows the modulation of Ob expression in adipose tissues prepared from nonpregnant (-NP) or pregnant (-P) hypertensive (SHR) or normotensive (WKY) rats. In $\mathrm{B}$, the modulation of $\mathrm{Ob}$ expression was shown in placentas from pregnant (-P) hypertensive (SHR) or normotensive (WKY) rats. Values are mean \pm S.E.M. of five animals. Equal loading was confirmed by $\beta$-actin staining. ${ }^{* *} P<0 \cdot 01$ versus WKY-NP; ${ }^{\circ} P<0.05$ versus SHR-NP; ${ }^{\# \#} P<0 \cdot 01$ versus WKY-P.

authors provide evidence, using RT-PCR, that placenta may be a further source of leptin in rodents and may explain the decrease of leptin levels after delivery (Hoggard et al. 1997, Garcia et al. 2000).

As reported by Kawai et al. (1997), during pregnancy in rats, maternal plasma leptin levels, measured every 3 days, gradually increased on days 9-19, when the peak leptin levels occur. Thereafter, maternal leptin levels sharply declined to less than those of nonpregnant animals. In our experimental conditions, at day 20 of pregnancy, we did not found differences between pregnant or not WKY leptinemia $(3 \cdot 30 \pm 0 \cdot 10$ vs $3 \cdot 00 \pm 0 \cdot 21$ respectively), even if a significant increase of leptin protein expression $(P<0 \cdot 01)$ was evidenced in s.c. adipose tissue. Moreover, we observed, for the first time using hypertensive animals, at day 20 , a twofold increase of serum leptin level $(1.16 \pm 0.14$ SHR-P vs $0.56 \pm 0.57$ in SHR-NP, $t=2 \cdot 965)$ that paralleled a significant increase of leptin gene expression in s.c. adipose tissue $(P<0 \cdot 05)$. This accounts for the highest
A
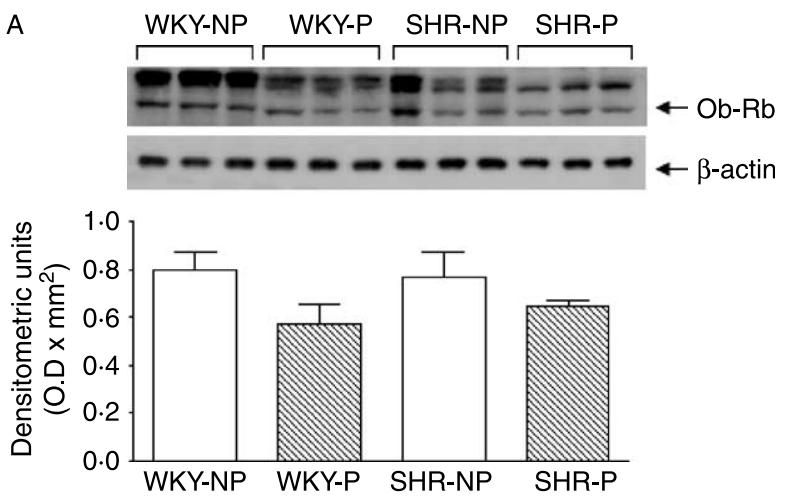

B
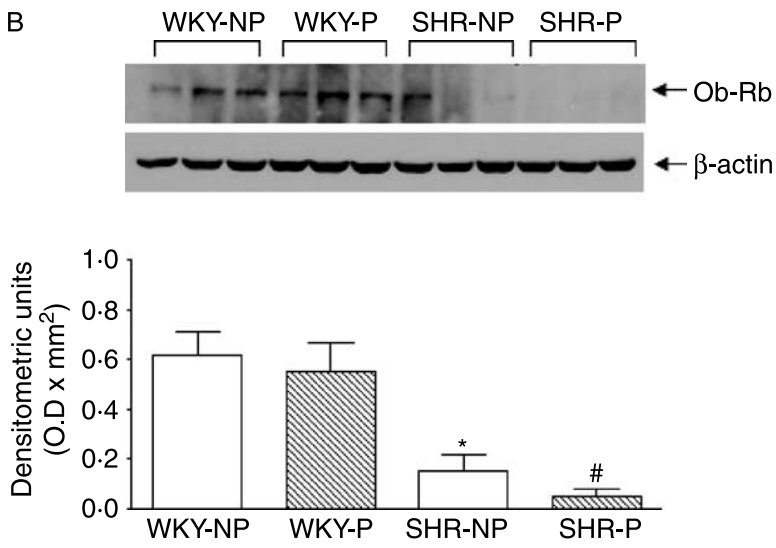

Figure 5 Western blot analysis of Ob-Rb expression and densitometric analysis of protein bands in (A) s.c. adipose tissue and (B) hypothalamus prepared from nonpregnant (-NP) or pregnant (-P) hypertensive (SHR) or normotensive (WKY) rats. Values are mean \pm S.E.M. of five animals. Equal loading was confirmed by $\beta$-actin staining. ${ }^{*} P<0 \cdot 05$ versus WKY-NP; ${ }^{\#} P<0 \cdot 05$ versus WKY-P.

amount of adipose tissue in the body and contributes to circulating leptin levels. However, SHR strain animals presented significantly lower plasma leptin when compared with those determined in WKY-NP and WKY-P controls. Interestingly, in the placenta compared with the plasma or adipose tissue, the opposite seemed to happen: leptin gene expression was higher in SHR-P than in normotensive animals. The increased plasma leptin concentration during pregnancy in SHR may be due to increased placental production. In pregnant SHR, increased serum leptin concentrations and expression of placental leptin in late gestation may seem paradoxical. If the organism were to respond to this satiety signal (e.g. increased leptin), food consumption would decline, and nutritional support for the mother and fetus would be compromised. Since food intake is not diminished in late pregnancy, an adaptive process appears to have evolved to maintain maternal and fetal well-being. In SHR-P, the increase of leptin in serum and tissues (adipose and placenta) is not accompanied by a food intake modification. One possible explanation of this discrepancy may be the resistance to the effects of leptin via 'downregulation' of 
A
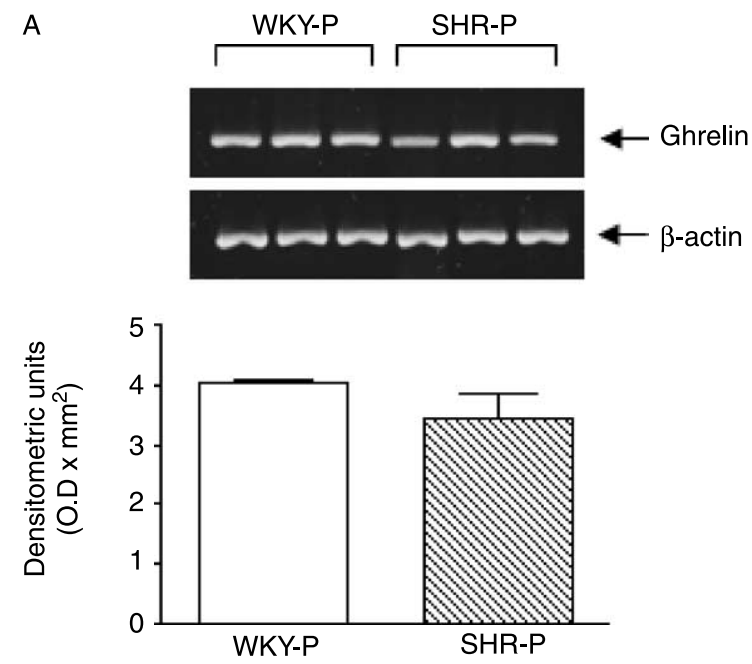

B
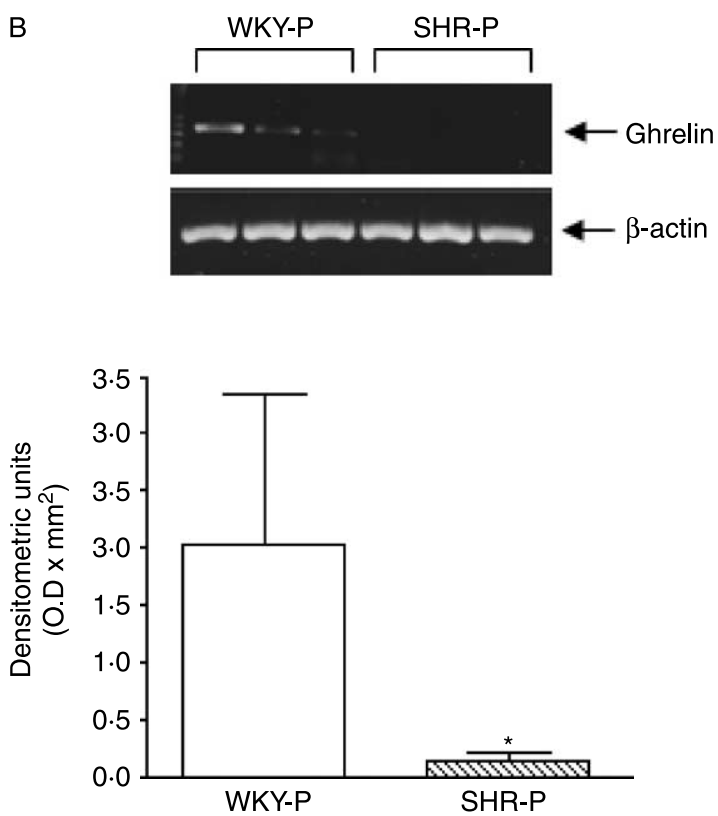

Figure 6 RT-PCR analysis of ghrelin $m R N A$ and its densitometric analysis in (A) stomach and (B) placenta from pregnant (-P) hypertensive (SHR) or normotensive (WKY) rats. Values are mean \pm S.E.M. of five animals. $\beta$-Actin was used as internal reference. $* P<0 \cdot 05$ versus WKY-P.

hypothalamic leptin receptors in pregnant SHR, as evidenced by the marked reduction of the hypothalamic expression of $\mathrm{Ob}-\mathrm{Rb}$ protein bands (Fig. 5). However, the possible involvement or alteration of other peptides or peripheral hormones, which regulate food intake, cannot be excluded. No significant modification of hypothalamic Ob-Rb expression was seen at day 20 of pregnancy in WKY, even if previous data are suggestive for leptin resistance in the hypothalamus and pituitary (Szczepankiewicz et al. 2006). Moreover, in our conditions, no significant modification of
$\mathrm{Ob}-\mathrm{Rb}$ expression was seen in adipose tissues either in normotensive or in hypertensive animals.

Previous data demonstrated that SHR is a strain that easily manifests hyperlipemia and hyperlipoproteinemia during pregnancy when compared with the Wistar rat (Yoshioka et al. 1986). In fact, many data suggest that in late pregnancy, liver lipid metabolism may be directed toward VLDL secretion at the expense of biliary secretion. This would supply lipids, especially triglycerides, to the placenta for fetal energy requirements and to the mammary gland for milk lipids in anticipation of suckling (Smith et al. 1998). This study compared the changes in the level of serum lipid concentration in pregnant and nonpregnant SHR and WKY rats. The serum triglyceride concentration is significantly higher in the last period of pregnancy, i.e. twofold higher in WKY and fivefold higher in SHR. It has been noted that elevated plasma lipid and lipoproteins may induce endothelial dysfunction secondary to oxidative stress and that dyslipidemia may impair trophoblast invasion, thus contributing to a cascade of pathophysiological events that lead to the development of pre-eclampsia (Lorentzen \& Henrisksen 1998). Consistent with our results on the lower leptin serum levels in SHR strain, Anderson et al. (2005) found a significant decrease of leptinemia in reduced uterine perfusion pressure (RUPP) animals. RUPP is an animal model of pre-eclampsia characterized by persistent elevation of arterial pressure, reduced litter size, fetal, and placental weights.

In opposite to leptinemia, our data show an increase of ghrelin plasma level in SHR strain when compared with that of WKY. In particular, in SHR at the end of day 20 pregnancy, we determined the bioactive (n-octanoyl modified) form of ghrelin and showed a slight increase of plasma hormone. Ghrelin has been shown to participate in cardiovascular and sympathetic regulation (Matsumura et al. 2003). Intravenous injection of human ghrelin elicits a decrease in blood pressure (Nagaya et al. 2001) with direct vasodilatory effects possibly through $\mathrm{GH}$ or nitric oxideindependent mechanisms (Okumura et al. 2002). However, in our experimental condition, this weak hormone increase could not account the deep fall of blood pressure evidenced in SHR-P before delivery. The full explanation for the fall in blood pressure occurring in pregnant SHR is unclear: probably other factors and mechanisms may be involved in pressure homeostasis, such as the placenta-derived hypotensor substances, modification of angiotensin-renin system or of endothelium-derived relaxing factors.

Confirming previous data in normotensive animals (Shibata et al. 2004), we observed that in SHR, as well as in WKY, the level of ghrelin peptide in the stomach did not change at the end of pregnancy in both strains. On the contrary, mRNA ghrelin in the placenta of SHR was lower than that of normotensive rats, suggesting not only that in the fetal-placental unit there is a different production of this hormone, but also that circulating levels are influenced by the release of ghrelin by other regions (i.e. intestinal tract, pancreas, or hypothalamus or pituitary). Therefore, in SHR, 
the production of placental ghrelin was not related to the plasma ghrelin concentration during pregnancy.

In conclusion, we observed an opposite profile of serum concentration of the examined hormones between WKY and SHR strains, showing a marked decrease of leptin and an increase of ghrelin level in either pregnant or not SHR. The inverse occurs in placenta expression of leptin: the higher production of leptin in pregnant SHR than in WKY might compensate the downregulated leptin system in SHRs. During pregnancy, SHRs presented an increase of body weight gain, paralleled to an increase of fat mass when compared with pregnant WKY animals, without a modification of food intake. Moreover, we found significantly higher plasma ghrelin levels in SHR that is not related to gastric or placental contribution. In contrast to the defined role of leptin and ghrelin in metabolic adaptations and dietary intake during pregnancy, their involvement in energy balance in hypertensive animals remains to be clarified.

\section{Acknowledgements}

The authors thank Joseph Sepe, MD, for assistance in revising the manuscript. This study was supported by a grant from the Ministero dell'Universita' e della Ricerca Scientifica e Tecnologica PRIN 2003, Italy. E E is at present a recipient of a grant by 'Centro Regionale di Competenza' 'Diagnostica e Farmaceutica molecolari', Regione Campania-Settore Scientifico, Italy. The authors declare that there is no conflict of interest that would prejudice the impartiality of this scientific work.

\section{References}

Ahokas RA \& Sibai BM 1990 The relationship between experimentally determined litter size and maternal blood pressure in spontaneously hypertensive rats. American Journal of Obstetrics and Gynecology 162 841-847.

Ahokas RA, Sibai BM \& Anderson GD 1989 Lack of evidence of a vasodepressor role for relaxin in spontaneously hypertensive and normotensive pregnant rats. American Journal of Obstetrics and Gynecology $161618-622$.

Anderson CM, Lopez F, Zhang H, Pavlish K \& Benoit JN 2005 Characterization of changes in leptin and leptin receptors in a rat model of preeclampsia. American Journal of Obstetrics and Gynecology 193 267-272.

Anim-Nyame N, Sooranna SR, Steer PJ \& Johnson MR 2000 Longitudinal analysis of maternal plasma leptin concentrations during normal pregnancy and pre-eclampsia. Human Reproduction 15 2033-2036.

Bajoria R, Sooranna SR, Ward BS \& Chatterjee R 2002 Prospective function of placental leptin at maternal-fetal interface. Placenta 23 103-115.

Brenner CA, Tam AW, Nelson PA, Engleman EG, Suzuki N, Fry KE \& Larrick JW 1989 Message amplification phenotyping (MAPPing): a technique to simultaneously measure multiple mRNAs from small numbers of cells. Biotechniques 7 1096-1103.

Caminos JE, Tena-Sempere M, Gaytan F, Sanchez-Criado JE, Barreiro ML, Nogueiras R, Casanueva FF, Aguilar E \& Diéguez C 2003 Expression of ghrelin in the cyclic and pregnant rat ovary. Endocrinology 144 1594-1602.

Chomczynski P \& Sacchi N 1987 Single-step method of RNA isolation by acid guanidinium thiocyanate-phenol-chloroform extraction. Analytical Biochemistry 162 156-159.
Conrad KP, Joffe GM, Kruszyna H, Kruszyna R, Rochelle LG, Smith RP, Chavez JE \& Mosher MD 1993 Identification of increased nitric oxide biosynthesis during pregnancy in rats. Federation of American Societies for Experimental Biology 7 566-571.

Erickson JC, Clegg KE \& Palmiter RD 1996 Sensitivity to leptin levels: relationship to plasma leptin and susceptibility to seizures of mice lacking neuropeptide Y. Nature 381 415-418.

Garcia MD, Casanueva FF, Dieguez C \& Senaris RM 2000 Gestational profile of leptin messenger ribonucleic acid (mRNA) content in the placenta and adipose tissue in the rat, and regulation of the mRNA levels of the leptin receptor subtypes in the hypothalamus during pregnancy and lactation. Biology of Reproduction 62 698-703.

Gaytan F, Barriero ML, Chopin LK, Herington AC, Morales C, Pinilla L, Casanueva FF, Aguilar E, Diéguez C \& Tena-Sempere M 2003 Immunolocalization of ghrelin and its functional receptor, the type $1 \mathrm{a}$ growth hormone secretagogue receptor, in the cyclic human ovary. Journal of Clinical Endocrinology and Metabolism 88 879-887.

Gerold M \& Tschirky H 1968 Measurement of blood pressure in unanaesthetized rats and mice. Arzneimittelforschung 18 1285-1287.

Glowinski GA \& Iversen LL 1966 Regional studies of catecholamines in the rat brain. Journal of Neurochemistry 13 655-669.

Gualillo O, Caminos JE, Nogueiras R, Seoane LM, Arvat E, Ghigo E, Casanueva FF \& Dieguez C 2002 Effect of food restriction on ghrelin in normal-cycling female rats and in pregnancy. Obesity Research 10 682-687.

Henson MC \& Castracane VD 2006 Leptin in pregnancy: an update. Biology of Reproduction 74 218-229.

Hoggard N, Hunter L, Duncan JS, Williams LM, Trayhurn P \& Mercer JG 1997 Leptin and leptin receptor mRNA and protein expression in the murine fetus and placenta. PNAS 94 11073-11078.

Ilagan J, Bhutani V, Archer P, Lin PKH \& Jen KLC 1993 Estimation of body composition changes during weight cycling by bioelectrical impedance analysis in rats. Journal of Applied Physiology 74 2092-2098.

Kawai M, Yamaguchi M, Murakami T, Shima K, Murata Y \& Kishi K 1997 The placenta is not the main source of leptin production in pregnant rat: gestational profile of leptin in plasma and adipose tissues. Biochemical and Biophysical Research Communications 240 798-802.

Laivouri H, Gallaher MJ, Collura L, Crombleholme WR, Markovic N, Rajakumar A, Hubel CA, Roberts JM \& Powers RW 2006 RWRelationship between maternal plasma leptin, placental leptin mRNA and protein in normal pregnancy, pre-eclampsia and intrauterine growth restriction without pre-eclampsia. Molecular Human Reproduction 12 551-556.

Lindheimer MD, Katz AI, Koeppen BM, Ordonez NG \& Oparil S 1983 Kidney function and sodium handling in the pregnant spontaneously hypertensive rat. Hypertension 5 498-506.

Lorentzen B \& Henrisksen T 1998 Plasma lipids and vascular dysfunction in preeclampsia. Seminars in Reproductive Endocrinology 16 33-39.

Makino Y, Hosoda H, Shibata K, Makino I, Kojima M, Kangawa K \& Kawarabayashi T 2002 Alteration of plasma ghrelin levels associated with the blood pressure in pregnancy. Hypertension 39 781-784.

Masuzaki H, Ogawa Y, Sagawa N, Hosoda K, Matsumoto T, Mise H, Nishimura H, Yoshimasa Y, Tanaka I, Mori T et al. 1997 Nonadipose tissue production of leptin: leptin as a novel placenta-derived hormone in humans. Nature Medicine 3 1029-1033.

Matsumura K, Tsuchihashi T, Fujii K \& Iida M 2003 Neural regulation of blood pressure by leptin and the related peptides. Regulatory Peptides 114 $79-86$.

Nagaya N, Kojima M, Uematsu M, Yamagishi M, Hosoda H, Oya H, Hayashi Y \& Kangawa K 2001 Hemodynamic and hormonal effects of human ghrelin in healthy volunteers. American Journal of Physiology 280 1483-1487.

Nakanishi N, Takagi M, Kusumoto M \& Sugino N 1980 Sodium metabolism of pregnant SHR: the second report-sodium intake, sodium space and change in blood pressure. Japanese Heart Journal 21578.

Nakazato M, Murakami N, Date Y, Kojima M, Matsuo H, Kangawa K \& Matsukura S 2001 A role for ghrelin in the central regulation of feeding. Nature 409 194-198.

Okamoto K \& Aoki K 1963 Development of a strain of spontaneously hypertensive rats. Japanese Circulation Journal 27 282-293. 
Okumura H, Nagaya N, Enomoto M, Nakagawa E, Oya H \& Kangawa K 2002 Vasodilatory effect of ghrelin, an endogenous peptide from the stomach. Journal of Cardiovascular Pharmacology 39 779-783.

Richard D \& Trayhurn P 1985 Energetic efficiency during pregnancy in mice fed ad libitum or pair-fed to the normal energy intake of unmated animals. Journal of Nutrition 115 593-600.

Rohner Jean Reaneaud F, Cusin I, Sainsburg A, Zakrewska KE \& JeanReanaud B 1996 The loop between NPY and leptin in normal and obese rodents. Hormone and Metabolic Research 28 642-648.

Shibata K, Hosoda H, Kojima M, Kangawa K, Makino Y, Makino I, Kawarabayashi T, Futagami K \& Gomita Y 2004 Regulation of ghrelin secretion during pregnancy and lactation in the rat: possible involvement of hypothalamus. Peptides 25 279-287.

Smith JL, Lear SR, Forte TM, Ko W, Massimi M \& Erickson SK 1998 Effect of pregnancy and lactation on lipoprotein and cholesterol metabolism in the rat. Journal of Lipid Research 39 2237-2249.

Szczepankiewicz D, Wojciechowicz T, Kaczmarek P \& Nowak KW 2006 Leptin and its receptors in the course of pregnancy in the rat. International Journal of Molecular Medicine 17 95-99.

Tanigawa K, Miura T, Ishihara E \& Kawaguchi M 1999 Effect of pregnancy on insulin metabolism in spontaneously hypertensive rats. Metabolism $\mathbf{4 8}$ 1339-1342.

Tartaglia LA 1997 The leptin receptor. Journal of Biological Chemistry 272 6093-6096.

Teppa RJ, Ness RB, Cromblehholme WR \& Roberts JM 2000 Free leptin is increased in normal pregnancy and further inceased in preeclampsia. Metabolism 49 1043-1048.
Trayhurn P, Hoggard N, Mercer JC \& Rayner DV 1999 Leptin: fundamental aspects. International Journal of Obesity and Related Metabolic Disorders $\mathbf{2 3}$ 22-28.

Wren AM, Small CJ, Ward HL, Murphy KG, Dakin CL, Taheri S, Kennedy AR, Roberts GH, Morgan DGA, Ghatei MA \& Bloom SR 2000 The novel hypotalamic peptide ghrelin stimulaters food intake and growth hormone secretion. Endocrinology 141 4325-4328.

Yamada N, Kido K, Tamai T, Mukai M \& Hayashi S 1981 Hypertensive effects on pregnancy in spontaneously hypertensive rats (SHR) and stroke-prone SHR (SHRSP). International Journal of Biological Research in Pregnancy 2 80-84.

Yoshioka T, Motoyama H \& Yamasaki F 1986 Lipid and lipoprotein metabolism in the pregnant rat. Nippon Sanka Fujinka Gakkai Zasshi $\mathbf{3 8}$ 311-316.

Zamorano B, Terragno A, McGiff JC \& Terragno NA 1980 A prostaglandin mechanism may contribute to the regulation of blood pressure in spontaneously hypertensive rats during pregnancy. Advances in Prostaglandin and Thromboxane Research 7 807-810.

Received 2 April 2007

Accepted 15 June 2007

Made available online as an Accepted Preprint

18 June 2007 